\title{
ELECTROCARDIOGRAPHIC AND RADIOLOGICAL STUDIES IN HIATUS HERNIA
}

\author{
BY \\ J. B. MCGUINNESS AND S. D. SCOTT PARK \\ From the Western Infirmary, Glasgow \\ Received December 8, 1959
}

The existence of hiatus hernia is being postulated by physicians and observed by radiologists much more frequently than in the past (Brick, 1949; Edmunds, 1957). This is largely due to an increased awareness of the existence of the condition and, as a result, the employment of special techniques for its demonstration. The incidence is illustrated in a survey by Brick (1949) in which 3488 examinations of the upper gastro-intestinal tract were reviewed: in these he found that hiatus hernia was the second most frequent diagnosis, occurring in 308 patients $(8.9 \%)$, while duodenal ulcer, by comparison, occurred in 705 patients $(20 \%)$.

The symptoms of hiatus hernia are numerous and variable and as a result the diagnosis is often missed. Thus in a series of 110 cases reported by Clerf et al. (1950) 35 were misdiagnosed when first seen. Chest pain and flatulence are often prominent and since this combination of symptoms is frequent in ischæmic heart disease, it is not surprising that in most descriptions of hiatus hernia, angina pectoris is mentioned when the differential diagnosis is discussed. In addition, hiatus hernia is most commonly found in the older age groups, the majority of cases being between 45 and 75 years of age (Edmunds, 1957). This resembles the incidence of ischæmic heart disease (Wood, 1956).

In view of the obvious difference in prognosis and management of these two conditions, it is important that they should be clearly differentiated. Electrocardiography and radiology might appear to make this distinction, but this is not always the case. For example it has been shown that distension of the stomach (Johnson and Laing, 1940) or of the œsophagus (Morrison and Swalm, 1940: Kohli and Pearson, 1952) can cause alterations in the conventional electrocardiogram. It has also been demonstrated that in dogs the coronary blood flow is diminished when the stomach is distended (Gilbert et. al., 1940): in that study a vagal reflex was held to be responsible. On the other hand, Bloom and Gubbay (1957) failed to demonstrate any effect on the electrocardiograms of fifteen patients recorded as they were actually swallowing a bolus of barium.

In view of this conflicting evidence we decided to study a random group of patients known to have hiatus hernia and investigate the effect on the electrocardiogram when the hernia was distended by a barium emulsion under fluoroscopic control.

\section{MATERIALS AND Method}

Twenty patients were studied as they presented at the out-patient department. Sixteen were women, aged 40 to 70 years, and four men, aged 40 to 55 years. This sex distribution is similar to that described by Edmunds (1957).

Details of the history and physical examination of each patient were recorded and particular attention was paid to chest pain when present. If this was of the pattern originally described by Heberden (1772) it was called cardiac pain.

Hæmoglobin and packed cell volume were estimated and any level below 80 per cent hæmoglobin was considered abnormal and was corrected by oral iron before the investigation proper was 
undertaken. This was considered important in view of the effect that anæmia has been shown to have on the electrocardiogram (Master and Jaffe, 1940; Master et al., 1947). Height and weight were measured, the weight later being compared with the estimated optimum for each patient.

The patients then attended for screening after a fast of at least four hours. An electrocardiogram was taken with the patient in the supine position on the X-ray table, before and after drinking a pint of fairly thick barium emulsion. A direct-writing electrocardiograph was used and twelve leads were recorded on each occasion: these were leads I, II, III, aVR, aVL, aVF, and VI-6.

During the screening after the emulsion was swallowed, the hernia was dilated to the maximum size possible by simple abdominal pressure, aided sometimes by tilting the patient's head down while in the left lateral position. When this manœuvre was neccessary the second electrocardiogram was recorded in the supine horizontal position. The size of the hernia was measured and its type noted on the patient's record. The chest was marked before starting to ensure that the position of the chest leads remained constant throughout. Each electrocardiogram was carefully standardized and following the second one, the hernia was rescreened to confirm that it had remained fully dilated.

In eight patients chosen at random, trinitrin (glyceryl trinitrate $1 / 120$ grain) was given at this stage. The behaviour of the hernia was watched and after a minimum of two minutes a third electrocardiogram was taken.

In several cases slight differences were observed between the original electrocardiogram and that taken after swallowing the barium. These patients were asked to return again after a fast of at least four hours and the effects of various procedures were observed. Further tracings were taken with the patient supine, supine and in deep inspiration, lying on the left side, in the Trendelenberg position, on the right side, with the patient upright, and lastly with the patient supine after exercise: this consisted in climbing on and off a nine-inch step 80 times or until forced to stop by dyspnœa or chest pain. These symptoms were in fact produced in each patient who had complaints indicative of cardiac pain of effort.

\section{RESULTS}

General. Of the twenty patients studied, a history of cardiac pain was obtained in five, one man and four women, a sex distribution similar to that of the whole group. It was interesting that the pain produced by exercise, although often similar in site to that produced by lying or stooping, was more severe in each of these patients.

When first seen, eight had a hæmoglobin of less than 80 per cent $(100 \%=14.5 \mathrm{~g}$. hæmoglobin per $100 \mathrm{ml}$.) A later estimation showed that treatment had brought it above this level. Six of the patients were overweight by more than 10 per cent.

Radiological Features. Any hernia that projected more than 5 centimetres above the diaphragm was considered to be large. There were eleven large herniæ of which five were sliding, one was rolling, and five were mixed. The nine small herniæ were all of the sliding variety.

Six of the twenty herniæ altered slightly in size during screening and presumably while the second electrocardiogram was being recorded. In no case was this sufficient to cause a small hernia to become large or a large one small.

Trinitrin produced a change in the hernia of one of the eight patients who received it. She developed free cesophageal reflux well seen on screening and accompanied by loud eructation and severe retrosternal pain. Her initial electrocardiogram showed S-T-T depression in leads aVL and V4-V6. No change was observed in this following the barium, but her third tracing, taken while the severe pain was present, showed improvement. This was the only patient in whom pain was produced.

Electrocardiographic Appearances. The initial electrocardiogram was abnormal in six patients before the hernia was filled. The abnormalities were flattening of the $\mathrm{T}$ waves in all leads in one, $\mathrm{S}-\mathrm{T}$ depression in V3-V6 and aVL in one, and occasional ventricular extrasystoles in a third. Three showed low voltage of QRS, in one of whom the P-R interval was prolonged.

In seven patients variations in the amplitude of the $T$ wave was noted. This happened in a regular manner, the $T$ wave increasing in size with each complex until a maximum was reached and then gradually 


\section{ELECTROCARDIOGRAM IN HIATUS HERNIA}

decreasing. These changes were present before and after visualization of the hernia and involved lead III alone in two, leads III and V1 in two, lead V1 in two, and leads V2-V4 in the remaining patient.

With distension of the hernia, changes were found in the electrocardiograms of six patients. In the original tracings, four of these were normal and two were abnormal. Two of the six had a history of cardiac pain on effort; the electrocardiogram of one showed ventricular extrasystoles and the other was within normal limits. No changes were observed in rate, rhythm, $\mathbf{P}$ waves, $\mathbf{P}-\mathbf{R}$ interval or S-T segment. The findings are fully set out in the Table and the changes illustrated by Fig. 1 and 2.

As already described, these patients returned for further examination. The one who showed ventricular extrasystoles when the hernia was dilated did not reproduce these. In the remaining five, minor changes were noted in lead III and to a lesser extent in lead aVF in most of the positions and on deep respiration. In two

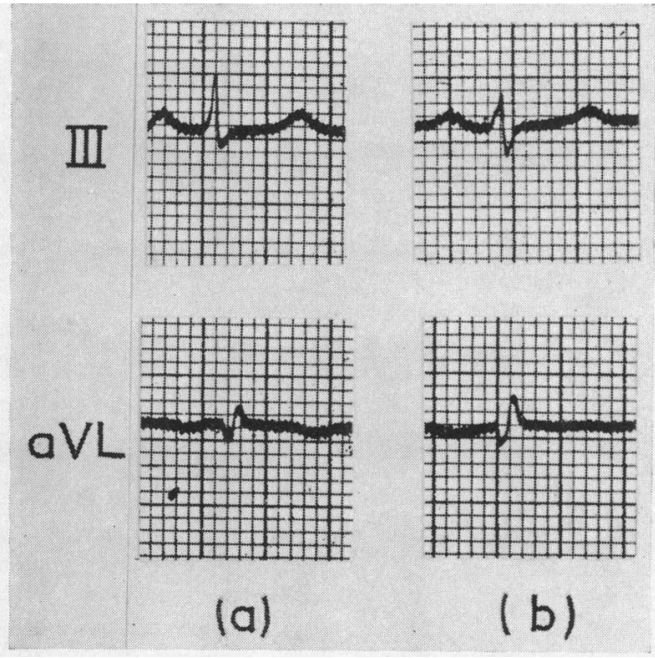

FIG. 1.-(a) Before swallowing barium.

(b) After swallowing barium.

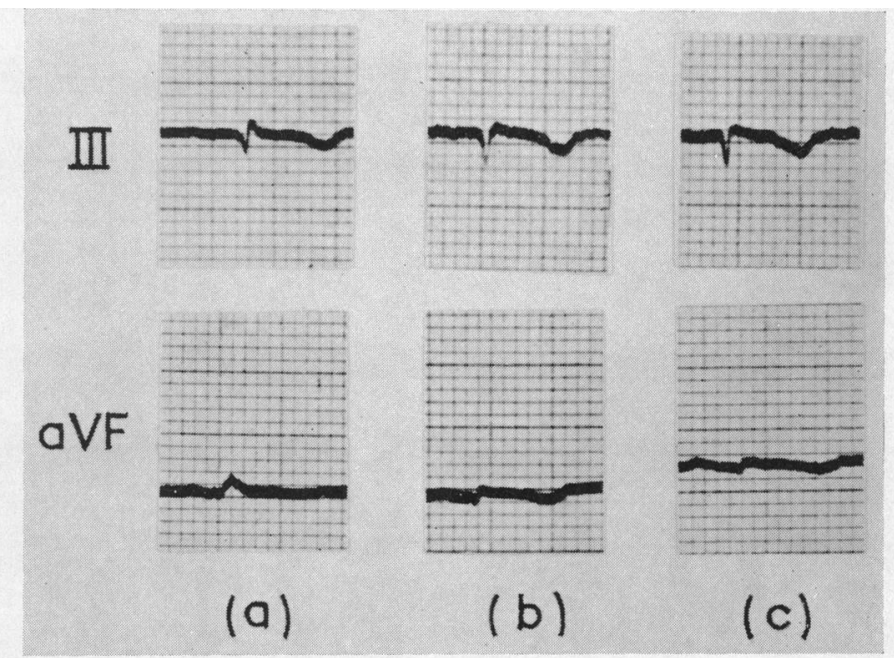

Fig. 2.-(a) Before swallowing barium. (b) After swallowing barium. (c) Two minutes after glyceryl trinitrate, hernia still full. Note the $T$ wave change in (b), unaltered by glyceryl trinitrate.

TABLE

Summary of the Findings in the Six Patients Showing Electrocardiographic Changes

\begin{tabular}{c|c|c|c|c|c|c}
\hline & Age & \multicolumn{1}{|c|}{ Initially } & After distension & After trinitrin & Hernia & Angina \\
\hline 1 & 65 & $\begin{array}{c}\text { T III inverted; flat } \\
\text { aVF }\end{array}$ & T III more deeply inverted & - & $\begin{array}{l}\text { Small \& } \\
\text { variable }\end{array}$ & Absent \\
\hline 2 & 58 & $\begin{array}{c}\text { T III and aVF in- } \\
\text { verted, T II flat }\end{array}$ & $\begin{array}{c}\text { T III \& aVF more deeply } \\
\text { inverted }\end{array}$ & No change & Small & Present \\
\hline 3 & 45 & $\begin{array}{c}\text { T III and aVF up- } \\
\text { right; Rs pattern } \\
\text { III, aVF }\end{array}$ & $\begin{array}{c}\text { T III \& aVF less tall; S III } \\
\text { deeper; R aVL taller }\end{array}$ & No change & Large & Absent \\
\hline 4 & 54 & T III inverted & $\begin{array}{c}\text { T III more deeply inverted. } \\
\text { S in aVF deeper }\end{array}$ & No change & $\begin{array}{l}\text { Small \& } \\
\text { variable }\end{array}$ & Absent \\
\hline 5 & 64 & Low voltage QRS & $\begin{array}{c}\text { Occasional ventricular } \\
\text { extrasystoles }\end{array}$ & No change & Large & Absent \\
\hline 6 & 47 & T III inverted & $\begin{array}{c}\text { T III more deeply inverted. } \\
\text { T in aVF flatter }\end{array}$ & - & Small & Present \\
\hline
\end{tabular}

All were women except the last. 
of them the changes produced by swallowing barium were reproduced when the patient stood and in one the change on standing resembled this appearance but was not quite so much. In another the initial electrocardiogram on the return visit showed $\mathrm{T}$ wave inversion in lead III equal to that noted after swallowing barium. This became less in every position except the standing and Trendelenberg positions. In the remaining one the changes seen after the barium swallow could not be reproduced.

In all five cases, exercise lessened the amplitude of the T wave in lead III and in one it became upright after being inverted. In the two in whom cardiac pain was produced, the electrocardiogram showed S-T depression of $1 \mathrm{~mm}$. in lead V4 in one and leads V4 and V5 in the other. The changes following exercise bore no resemblance to those found after dilatation of the hernia.

Thus standing reproduced the change in two and produced a similar change in one of the five cases. One might be said to have a tendency in that direction while the other showed no similar change. The well known tendency of lead III to vary with position was incidentally demonstrated. An example of these changes is shown in Fig. 3.

Two of these five patients exceeded their optimum weight by more than ten per cent.

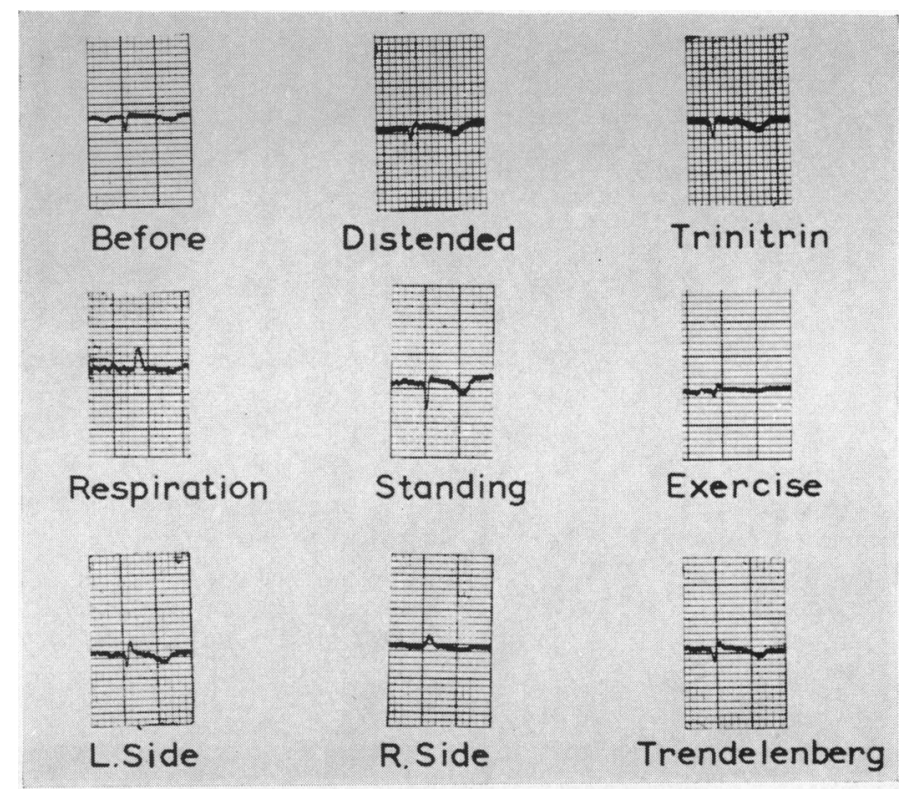

FIG. 3.-Changes in lead III in one of the cases studied.

\section{Discussion}

Gastro-intestinal symptoms have long been associated with disease of the cardiovascular system. Osler (1897) noted that, as an attack of angina pectoris ended, the patient might belch quantities of gas or pass flatus from the bowels, both with apparent great relief. Much significance was given to this clinical observation by Verdon (1920) who claimed that angina pectoris was due to acute spasmodic inco-ordinated contraction of the œsophagus and stomach. This was investigated experimentally by Jackson and Jackson (1936) who concurred with the view.

As already mentioned, various stimuli have been applied to the œsophagus and stomach and the electrocardiographic effects observed. By producing pain by balloon distension of the stomach in five patients, two with myocardial disease, Johnson and Laing (1940) have demonstrated changes in the $\mathrm{T}$ wave in three and the QRS complex in one, all in lead III. It was thought that these alterations might be due to a change in the position of the heart. Using a similar technique, Morrison and Swalm (1940) produced electrocardiographic changes in two out of four patients with cardiac disease while the balloon was in the œsophagus. These findings were less convincing, one 
showing sinus block and ST-T depression recorded while the patient was fainting, the other showing a left ventricular strain picture but with no control for comparison.

By distending hiatus herniæ by a balloon, Kohli and Pearson (1952) produced the picture of cardiac rotation in two and myocardial ischæmia in two patients out of a total series of eight. They went on to reproduce the ischæmic picture in the last two patients by exercise.

In planning our investigation, the barium method was chosen in preference to the others since it was considered less likely to disturb the patients. In addition, the degree of gastric filling that was simultaneously achieved was considered an advantage in that the circumstances produced were more comparable with those occurring spontaneously in the patient than the state produced by distending the œsophagus or hernia.

Our findings in this series appear to follow the general pattern already described, five of the six changes affecting lead III, four of these involving lead aVF. This type of change had been produced by altering the position of the patient (Goldberger, 1954). It seemed possible that the changes in our patients were due to slight alterations in the position of the heart since standing was found to reproduce the pattern in four patients. The great tendency of lead III to alter with position was again demonstrated.

The possibility that these changes were due to myocardial ischæmia following a reflex coronary constriction had to be considered. If this were the reason, one would have expected some deviation in the S-T segments. This was not seen in any case. In addition, had this been the explanation, the changes following exertion should have resembled those found when the herniæ were dilated. This was not so and in each case the $T$ wave inversion, when present, became less following exercise. The fact that cardiac pain was produced by this procedure in the two patients with this complaint shows that, in these two at least, myocardial ischæmia had been produced. In these patients this was further proved by S-T depression in the præcordial leads.

On the other hand, if the changes are attributed to alteration in cardiac position one wonders why the greatest differences were not seen in the eleven patients with larger herniæ. The most likely explanation is that by the method we used, many of these hernix were not adequately filled and that had they been firmly distended by a balloon they would have caused changes. In support of this, of the six patients exhibiting alterations in the electrocardiogram the one with the appearance most suggestive of positional change was found to have the largest hernia (Fig. 1; Table, Case 3).

The spontaneous variations in $T$ wave that we observed in seven instances have been found by others, but serve to illustrate once more the possible danger of comparing very short strips of electrocardiographic record. These changes have been clearly demonstrated by Bloom and Gubbay (1957) while their patient was in deep inspiration and no hernia was visible. It would then appear that neither of these factors could be held responsible.

Again, although our aim was not to reproduce symptoms, it was interesting that the only patient in whom these occurred had very free osophageal reflux following trinitrin. Assuming that in some patients with hiatus hernia chest pain can be caused at times by osophageal spasm, we might expect trinitrin to bring relief by relaxing it and, in this case, œsophageal relaxation of a striking degree was observed. It is well known that some sufferers do in fact obtain relief when trinitrin is administered and it would not be surprising if this type of pain, as a result of its response, were confused with the pain of myocardial ischæmia.

Our results in this small series lead us to the conclusion that the electrocardiogram may be influenced by the presence of a hiatus hernia. These changes are likely to be seen in lead III and. from the behaviour of the electrocardiogram under the experimental conditions described, we feel that change in heart position is the most probable explanation for them.

\section{SUMmary}

The investigation by radiology and electrocardiography of twenty patients known to have hiatus hernia is described. After an initial electrocardiogram each patient swallowed a pint of thick barium emulsion and a further record was taken when the hernia was filled. 
In six patients electrocardiographic changes were produced by this procedure involving lead III in particular.

These findings are discussed and it is concluded that in the presence of a full hiatus hernia, alterations may occur in the electrocardiogram. These are attributed to positional changes and are considered unlikely to be confused with the changes of ischæmic heart disease.

We would like to thank Dr. J. H. Wright for his great assistance, also Dr. J. D. Olav Kerr who suggested this study and Professor E. J. Wayne for their criticism and advice.

\section{REFERENCES}

Bloom, J., and Gubbay, E. (1957). Amer. Heart J., 54, 915.

Brick, I. B. (1949). Mississippi V. med. J., 71, 2.

Clerf, L. H., Shallow, T. A., Putney, F. J., and Fry, K. E. (1950). J. Amer. med. Ass., 143, 169.

Edmunds, V. (1957). Quart. J. Med., 26, 445.

Gilbert, N. C., Fenn, G. K., and LeRoy, G. V. (1940). J. Amer. med. Ass., 115, 1962.

Goldberger, E. (1954). Unipolar Lead Electrocardiography. 3rd ed., Lea and Febiger, Philadelphia.

Heberden, W. (1818). Commentaries on the History and Cure of Diseases. Wells and Lilly, Boston.

Jackson, D. E., and Jackson, H. L. (1936). J. Lab. clin. Med., 21, 993.

Johnson, C. A., and Laing, G. H. (1940). Amer. Heart J., 20, 160.

Kohli, D. R., and Pearson, C. C. (1952). Gastroenterology, 23, 294.

Master, A. M., and Jaffe, H. J. (1940). J. Mt. Sinai Hosp., 7, 26.

Master, A. M., Dack, S., Grisham, A., Field, L. E., and Horn, H. (1947). J. Mt. Sinai Hosp., 14, 8.

Morrison, L. M., and Swalm, W. A. (1940). J. Amer. med. Ass., 114, 217.

Osler, W. (1897), Lecture on Angina Pectoris and Allied States. D. Appleton and Co., New York.

Verdon, W. (1920). Angina Pectoris. Baillière, Tindall and Cox, London.

Wood, P. (1956). Diseases of the Heart and Circulation. 2nd ed., Eyre and Spottiswoode, London. 